\title{
American Pediatric Society Presidential Address at the 100th Annual Meeting: Let the Walls Come Tumbling Down'
}

\author{
MELVIN M. GRUMBACH
}

Department of Pediatrics, University of California, San Francisco, San Francisco, California 94143-0106

Members and guests, it is a privilege and honor to have served as your President and to deliver the 1990 Presidential Address at the 100th Annual Meeting of the American Pediatric Society. To paraphrase that well-known philosopher Woody Allen, "I don't mind giving a Presidential Address, I just don't want to be there when it happens." I thought long and hard about the topic - a humbling experience, but all part of the "Presidential Address Syndrome." These recurrent thoughts were interrupted by magnitudinous events in the San Francisco Bay area. Although my thoughts were not earthshaking, the events were: the 7.1 Loma Prieta earthquake on October 17; the award of the Nobel Prize in Medicine and Physiology to Michael Bishop and Harold Varmus, colleagues at the University of California, San Francisco; the Bay Bridge World Series (a minor distraction, since the Giants lost in four straight); and the San Francisco 49ers' victory in Super Bowl XXIV.

But with the 1980s safely behind me, as is the wont of Presidents preparing their remarks, I turned my thoughts to the origins and history of the American Pediatric Society. As a teenager, I knew that I wanted to be a physician involved in the care of children, and I took the first steps on a path that eventually led me to academic pediatrics. My selection of pediatrics may have been foreordained, for I discovered that Dr. Henry Koplik (1858-1927), a founding member member of our Society and its 12 th President, was my pediatrician. A graduate of the Columbia College of Physicians and Surgeons, Dr. Koplik practiced in New York City. A champion of clean milk, he established the first "sterilized" milk depot (later adopted throughout the world). A venerated teacher and clinician, an expert in infectious diseases, an author of a textbook of pediatrics, and a describer of Koplik spots, he was one of the first physicians in New York City to have a laboratory in his office. I think he would be proud of the American Pediatric Society today.

The title of my speech is "Let the Walls Come Tumbling Down." During the last year, we have witnessed extraordinary and largely unanticipated political change in Central and Eastern Europe. A revolution, largely peaceful, liberated millions of people and dramatically reduced the tensions of the Cold War and the risk of a nuclear holocaust. The "tumbling down" of the Berlin Wall stands as a vivid symbol of this decisive change. Let me suggest to you that this and other political and social events will be surpassed as the hallmark of the past 50 years, if not of this century, by another revolution-a scientific and technologic revolution-that promises to be the key component in shaping our society and indeed international affairs.

A special aspect of the rise in science and technology is the revolution in biology and its impact on biomedical science. Extraordinary advances in molecular genetics have provided a technology that has integrated biochemistry, genetics, and cell biology. They have engendered the "new biology," a conceptual

Correspondence: Melvin M. Grumbach, M.D., Department of Pediatrics, University of California, San Francisco, San Francisco, CA 94143-0106.

'Presented May 8, 1990. framework that can be applied to virtually any biologic system, and a new language to go along with it. These developments have had a dramatic and immutable effect on developmental biology, cancer biology, endocrinology, neurobiology, immunology, and many other areas. The rate of progress is literally mind boggling and has resulted in new insights into fundamental mechanisms of gene action and regulation, cell growth and differentiation, cell communication, peptide synthesis, the diagnosis and treatment of heritable disorders, and diagnostic and therapeutic agents, to name but a few.

I wish to address two issues: 1 ) the challenge of the revolution in biology on the development of the next generation of pediatric scientists and 2) the potential impact of pediatric scientists on the organization of academic pediatric departments. We are on the cusp of the 21 st century and the threshold of enormous change in biomedical science. The opportunities for advances that promise to influence childhood diseases are incalculable. We need more science not less science in pediatrics if we are to continue to take part in this logarithmic phase of biomedical progress.

To participate in this exciting and productive era in biomedical research, we need pediatric scientists who are well qualified and capable of making significant contributions. In my view, this will require a drastic restructuring of the way we train the next generation of pediatric scientists. The giants of pediatrics in the late 19 th and early 20th century, Jacobi, the elder Holt, and Howland, established pediatrics in the United States and illuminated it with their scientific contributions. They gave way to a host of pediatric scientists trained in chemistry, biochemistry, physiology, and microbiology. These men and women have made and continue to make landmark contributions to our knowledge of the pathophysiology, pathogenesis, and treatment of diseases of childhood.

However, the new advances are rapidly shifting the direction of progress in biomedical science away from the M.D.-investigator in such fields as human genetics, endocrinology, immunology, cancer biology, and neurobiology toward the Ph.D. scientist. In general, the Ph.D. scientist is less interested in or committed to the study of disease biology. Moreover, most pediatric departments, as well as other clinical disciplines, have been slow to adapt these radical changes and emerging technologies. If we do not rectify the deficiencies in the training of pediatric scientists, our contribution to this revolution and its application to pediatrics and human developmental biology will be in jeopardy. We will be on the side lines, merely onlookers, at one of the most momentous developments in the history of biomedical science. We will be isolated from the mainstream of contemporary biomedical science, unprepared to explore many important issues in human biology and the fundamental aspects of childhood disease that can be addressed through the concepts and technology of molecular genetics. Academic pediatrics will become less attractive to our brightest, most talented, and highly motivated medical students. We need pediatric scientists rigor- 
ously trained in the new biology to shatter the walls between pediatrics and basic science departments, foster interchange, and bring the excitement and ferment of the basic sciences and their new conceptual framework and language to our departments. We cannot afford to limit the scientific horizons of future pediatric scientists by clinging to traditional training programs. These programs are based on the orthodoxy and approaches of previous decades, approaches that once met the need but are now outdated and inadequate.

The new biology is important to the advancement of pediatric science. This is a young discipline, currently underrepresented in subspecialty areas of pediatrics, but with enormous potential to contribute to pediatrics and the scientific climate of our departments in the future (Fig. 1).

Parenthetically, let me emphasize that the new biology is not the only discipline that needs strengthening in academic pediatrics. Most of my scientific career has been devoted to regulatory biology, neuroendocrinology, and systems physiology. I am well aware of the ongoing contributions to be made in these areas to pediatrics and human biology. We will need a cadre of pediatric faculty who represent the best in regulatory biology and clinical investigation to study in vivo the clinical relevance and applications of the extraordinary advances in molecular and cell biology. We cannot afford to let them become an endangered species. We have much to learn about physiologic systems and their development and integration and communication networks, and their dysfunction in disease. For this knowledge, we will continue to look to the pediatric physiologist and regulatory biologist. The powerful reductionist approach does have its limits; broad frontiers remain unexplored in human and animal physiology. In human behavioral science, clinical epidemiology, and health policy, we need highly trained academic pediatricians who are well accultured to the scientific base of these fields. Clinical investigators will be responsible for evaluating new approaches to diagnosis, prevention, and therapy emerging from the cascade of developments in biotechnology and bioengineering. They will need to have a firm foundation in experimental design, computer science, biostatistics, and biomedical ethics. They will need to serve critically, effectively, imaginatively, and with distinction as a conduit of the dramatic new developments from the laboratory bench to the bedside and clinic. They will need to be possessed of informed skepticism, immense curiosity, and critical attitudes toward conventional wisdom so that they can separate passing fads from the real advances of the future.

What are some of the ways we can address the issue of the develc oment of the pediatric scientist? Let me describe one that already has had an amplifying effect.

In 1983, a small group of chairmen of pediatric departments commented on the scarcity of young academic pediatricians in a variety of subspecialty areas who were either qualified for or successful in obtaining National Institutes of Health (NIH) research funds. There was broad consensus that the deficiency in well-trained young academic pediatricians had reached crisis proportions and uniform agreement that a major, if not the most significant, factor was the lack of sufficient training in basic research. In March 1984, in an attempt to confront this critical issue and in response to the growing concern by its membership, the Association of Medical School Pediatric Department Chairs (AMSPDC) established a task force headed by Fred Battaglia and composed of pediatric chairs and established pediatric scientists (Table 1).

The AMSPDC Task Force had the enthusiastic support of Dr. Duane Alexander, Director of the National Institute of Child Health and Human Development (NICHD), the American Pediatric Society, and the Society for Pediatric Research. Seed funds were provided by the March of Dimes Birth Defects Foundation, Ross Laboratories, Mead Johnson, the American Board of Pediatrics, and personal contributions from pediatric chairs (and you know how hard it is to get a buck out of them). The Task Force developed a database and identified three broad areas for study: entry level, training, and research support. By late fall 1985, the Task Force had formulated a program and prepared a grant proposal.

The AMSPDC Task Force recognized the complexity of the problem of developing pediatric investigators competent in the basic sciences, especially when the commitment to this career pathway is not made until the housestaff years. While the task force was formulating its proposal, the ad hoc NIH Committee on Clinical Research Training issued its report to the Director of the NIH recommending the establishment of a "Progressive Training Pathway":
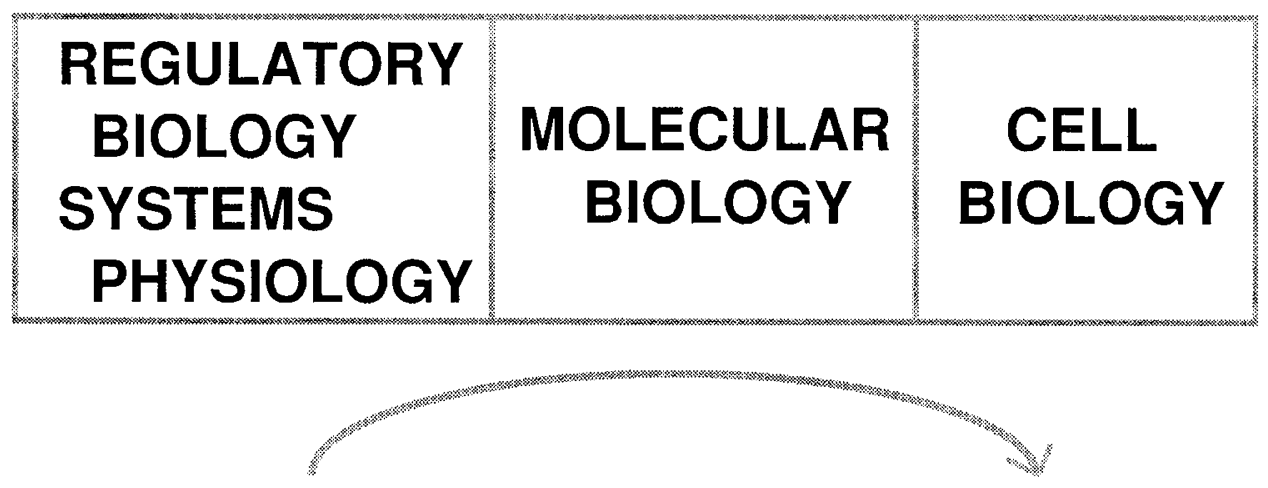

\section{Regulatory Biology Systems Physiology}

\section{Cell Biology}

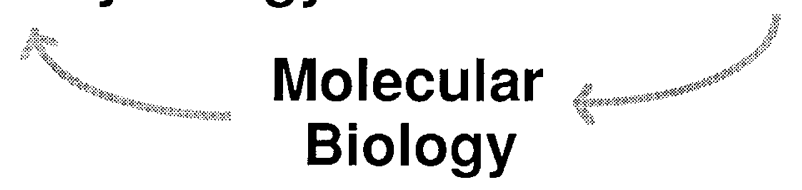

Fig. 1. Regulatory biology/systems physiology representative of holistic research and molecular biology, and cell biology representative of the reductionist approach are not isolated disciplines as represented in the top diagram but complement each other as illustrated in the lower diagram. In formulating and testing hypotheses, illuminating processes at their fundamental level, and assessing biologic and clinical relevance, there are great opportunities for interaction and cross-fertilization. 
Table 1. The task force for PSTP (April 1984)

$\begin{array}{ll}\text { Frederick C. Battaglia, Chairman } & \text { University of Colorado } \\ \text { Dennis M. Bier } & \text { Washington University } \\ \text { Thomas F. Boat } & \text { University of North Carolina } \\ \text { Saul W. Brusilow } & \text { Johns Hopkins University } \\ \text { Melvin M. Grumbach } & \text { University of California, San } \\ & \text { Francisco } \\ \text { Kurt Hirschhorn } & \text { Mount Sinai School of Med- } \\ & \text { icine } \\ \text { Larry J. Shapiro } & \text { University of California, Los } \\ & \text { Angeles } \\ \text { Michael A. Simmonds } & \text { University of Utah } \\ \text { Joseph B. Warshaw } & \text { University of Texas, Dallas }\end{array}$

Charge: Construct a postdoctoral training program that will serve to revitalize, invigorate, and renew the career development of future pediatric scientists under the auspices of the AMSPDC.

It is almost implicit in the nature of training $\mathrm{Ph} . \mathrm{D}$. scientists that training take place in more than one laboratory over the course of pre- and postdoctoral training. Such an eclectic exposure to research approaches is seen in the background of many successful physician scientists. Accordingly, it is proposed that as an additional step or option in the advanced training program, an opportunity be provided for research training in another laboratory for up to 2 years.

Independently, the Task Force had come to the same conclusion; this approach, although only a beginning, is an entry level for rigorous training in basic research for future pediatric scientists. It is an approach that could provide support for this type of experience for the more than half of our present subspecialty training programs that currently do not have a basic science component. It is a partial response to the "toe in the water" approach to clinical research training that so concerned Dr. James Wyngaarden when he was Director of the NIH.

Results of a survey of pediatric chairs, prepared by Dr. Larry Shapiro for the Task Force in 1985, indicated that the mean estimate of new appointments for academic pediatric scientists over the next 5 years was seven per department. In 1989, 37\% (or 684) of 3rd and 4th year residents planned to enter a fellowship program, according to a survey carried out by Ross Laboratories $(60 \%$ response rate). The percentage of residents who indicated their intention to begin fellowship training in the 1984 through 1988 pediatric housestaff surveys was similar (31-33\%). These surveys provide evidence of a compelling need for welltrained academic pediatric scientists and a potentially large pool of entry-level candidates. However, in assessing the majority of presently constituted fellowship training programs, it appears that many are essentially subspecialty residencies or clinical traineeships rather than fellowships with the capacity to produce graduates who can fill the role of academic pediatric scientist. Most programs focus exclusively on research training in a clinical department. Few are structured to provide graduates with the requisite foundation in contemporary biomedical science needed to being the long, demanding, arduous climb to success as independent investigators, or to bring competence in basic science into the specialty areas of pediatrics.

A novel program called the Pediatric Scientist Training Program (PSTP) was proposed to provide 5 years of support for applicants who have completed a pediatric residency and are committed to an academic career in a pediatric subspecialty (Table 2).

The essential components of the program are as follows: 1 ) Two years of research training and education in a basic science laboratory of a well-recognized senior biomedical scientist who serves as a mentor, preferably at a different university than the one where the candidate completed a pediatric residency. The importance of mentors and their role in indoctrinating young investigators in the approach to identifying important research
Table 2. Aims of PSTP

- To increase awareness of the opportunities for careers in pediatric research by pediatric residents.

- To facilitate entry into a research training environment under the mentorship of an outstanding biomedical scientist.

- To enhance the success of the training program by the selection process, by placement in a superb basic science laboratory, by interim counseling, by the commitment of the pediatric department and institution sponsoring the candidate, and by linking the program to subspecialty accreditation.

- To provide the foundation for a productive career as an academic pediatric scientist.

Table 3. Sponsors of PSTP through AMSPDC

Federal: NICHD

Other sponsors:

American Academy of Pediatrics (1986)

Cystic Fibrosis Foundation (1986)

Johnson \& Johnson Institute for Pediatric Service (1990)

March of Dimes, Birth Defects Foundation (1986)

St. Jude Children's Research Hospital (1986)

William T. Grant Foundation (1987)

Current annual budget: $\sim \$ 1000000$

Source of funds:

$50 \% \mathrm{NIH}$

$50 \%$ Other sponsors

Table 4. Number of PSTP fellows

\begin{tabular}{ccc}
\hline Year & 1st y & 2nd y \\
\hline 1987 & 7 & \\
1988 & 7 & 7 \\
1989 & 6 & 7 \\
1990 & 10 & 6 \\
Total & 30 & \\
\hline
\end{tabular}

problems that merit study cannot be overemphasized. Sir Peter Medawar in his book, Advice to Young Scientists, writes, “. . . any scientist of any age who wants to make important discoveries must study important problems... the problem must be such that it matters what the answer is-whether to science generally or to mankind." 2) One year of clinical fellowship training in a pediatric subspecialty area to provide subboard eligibility. 3) A junior faculty level position at the sponsoring institution that has the responsibility of providing support from extramural or departmental funds for at least 2 years and must ensure that at least $75 \%$ of the time is devoted to research.

The NIH grant, with Dr. Battaglia as Principal Investigator, was approved in 1986. Mrs. Monica St. Geme accepted the position of Executive Director, and the success of this program is due in no small measure to her effort, devotion, and outstanding administrative skill and the gifted leadership of Dr. Battaglia.

Funding for the program is provided by a consortium including NICHD, private, and institutional funds (Table 3). One half of the annual $\$ 1000000$ budget for the basic science training phase is provided by the NICHD and the remainder from five foundations and the American Academy of Pediatrics. It is especially notable that the leadership of the American Academy of Pediatrics representing pediatric practitioners has expressed its commitment to the future of academic pediatrics in such a tangible way. "Let the Walls Come Tumbling Down."

The program is directed by a steering committee that sets policy and monitors selection and evaluation committees.

As of May 1990, 30 fellows are either in the basic science training component or have completed their 2 years (Table 4). Our critical evaluation committee and the NICHD observers have been enthusiastic about its progress. Several of the PSTP fellows have elected to remain in the basic science laboratory for 
a 3rd year. When possible, NICHD has agreed to provide a $3 \mathrm{rd}$ year of support and starter grants for selected trainees.

Finally, the early success of this program and the close working relationship of the NICHD representatives with the PSTP played a major part in the development of the Child Health Research Center initiative by NICHD, inspired departments of obstetrics and gynecology to launch a similar program, and influenced activation of the new Postdoctoral Research Fellowship for Physicians Program sponsored by the Howard Hughes Medical Institute (Fig. 2).

The Child Health Research Center's initiative is designed to provide a better mechanism of support for young academic pediatric scientists in the transitional phase from fellow to independent investigator, increase the number and effectiveness of pediatric investigators with strong foundation in basic science, and strengthen basic science in pediatric departments. The aim is to speed the application of advances in basic science to the health care of children.

Some asides about the PSTP. Its purpose is not to emblazon the double helix as the new logo of the Department of Pediatrics but rather to ensure an intense exposure for fellows to the fundamental disciplines bearing on the clinical problems they plan to pursue, from molecular biology to the behavioral and biosocial sciences. Indeed, the William Grant Foundation supports those fellows who elect to train in behavioral science.

There have been rumblings of disparagement from some in the biomedical science community accusing the practitioners of the new biology of "mindless cloning," "destructive snobbery," "unbridled technologic exhibitionism," and "intellectual and scientific arrogance." One such critic wrote a letter to Science saying that "molecular chauvinism is leading down the road to scientific extinction." I do not think our Fellows are becoming "molecular chauvinists"; neither are my colleagues in basic science departments, who are leading exponents of the new biology. But I would urge you to learn the language!

In his 1959 Rede Lecture, C. P. Snow described the canyon between two cultures, the "science culture" and the "literary culture" or "art." Despite the popularity of his theme, it is only recently that his idea has been subject to serious criticism. Tom Stoppard's latest play "Hapgood" uses the "dualities of quantum physics as a metaphor for the duality in people." It is a striking example of why science and the humanities are not things apart but both vital components of our culture.

However, today there is disquieting evidence in some medical schools of an enlarging chasm between the clinician-scholar/ clinical investigator and the basic scientist practitioner of the new biology. This breach must be healed. We must look to the

Pediatric Scientist Training Program Fellowship Program (1986)

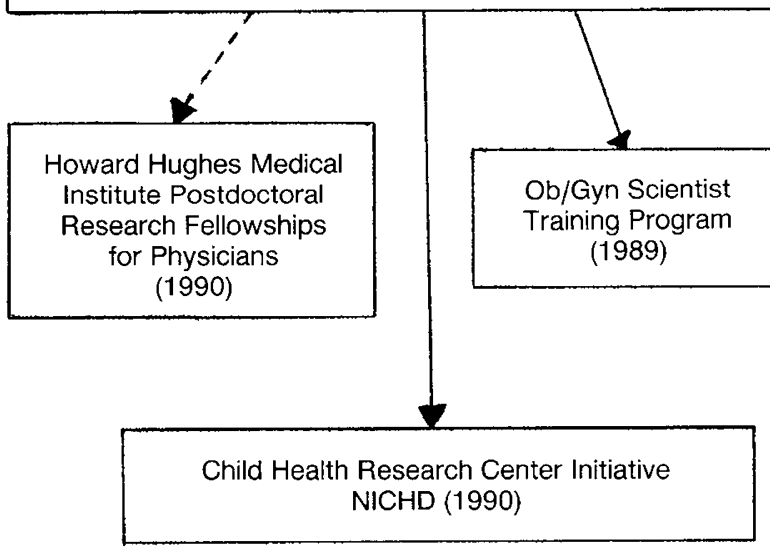

Fig. 2. The PSTP has served as an impetus for the development of new programs to strengthen the scientific background and opportunities of physicians committed to a career in academic pediatrics. pediatric scientist well grounded in the basic biomedical sciences to heal it. This can be accomplished by establishing meaningful liaisons with the basic biomedical science community, exploiting the concepts and technology of the new biology in excellent goaloriented research on disease biology and human development, and functioning as communicators and interpreters of the advances in basic biomedical science within departments of pediatrics. Academic pediatrics, by virtue of many mutual interests, can have a leading role in breaking down the barriers between the clinical and basic science departments and can promote interchange among the various disciplines.

Medicine and the biomedical and biosocial sciences are not cultural isolates. They have a social contract with society that includes a moral obligation. As pediatricians in academic medicine, we are engaged by society to use our ability, compassion, experience, skills, and creativity to advance the frontiers of medical knowledge and the application of these advances to health care.

To paraphrase Timothy Ferris, at the end of the second millenium, "biomedical science is our equivalent of painting in Michelangelo's day, of music in the time of Bach, of sea faring in the age of Prince Henry the navigator." I chose as the topic of the President's Symposium for this meeting "The New Cell Biology: A Frontier for Pediatric Research in the 90s." It was designed to convey some of the recent advances, power, excitement, and highly structured logic of the revolution in biology.

What is the potential impact of strengthening the cadre of pediatric scientists in departments of pediatrics?

Over the past two decades, a dramatic change has occurred in the structure, function, and complexity of the academic medical center including its relationship to the medical school and university. What has emerged is a mutual interdependency of what once were relatively independent and defined functions-research, education, clinical care (almost all of which is provided by full-time and geographic faculty), and hospital services. There has been extraordinary growth of faculty in clinical departments including pediatrics. This growth, at least in part, is a response to the complex technology-based patient care that has become the cachet of the academic medical center and of the expanded practice responsibilities and opportunities. Both of these factors have led to internal stress and conflicting agendas. Income from patient care activities has increased more than 15-fold in many pediatric departments. It now far surpasses federal research funds for the support of faculty engaged in research even in those pediatric departments that historically have been leaders in research. If research and scholarship are to prosper in academic pediatrics, a portion of monies generated through patient care activities by subspecialities with substantial earning capacity must be used to support other less lucrative subspecialty groups within the department including academic pediatric scientists. I count on the tradition of collegiality, common purpose, and moral suasion within departments of pediatrics to make possible a balance of subspecialty areas to support research, education, and patient care responsibilities. Simultaneously, we must cultivate and sustain a spirit of creative scholarship.

There are four broad categories of pediatric faculty: the clinical investigator, the pediatric scientist, the clinician-scholar, and the administrator-manager. All have a commitment to education, patient care, and scholarship with much diversity in the proportion of time and effort a given faculty member is expected to devote to each of these activities. Commonly, subspecialty units are composed of individuals from each of the first three categories in variable proportions, which allows a division of responsibility. In this era, we recognize the rarity of the renaissance faculty member, the triple threat individual of earlier generations. Although the development of this type of uniquely gifted individual remains an aspiration, we must take full advantage of the varied talents of each faculty member.

The time-honored role of the clinical investigator and the clinician-scholar in our departments is well known to all of us. 
To the clinician-scholars, I would say, just as compassion does not end at the laboratory door, neither does scholarship and an inquiring mind end at the bedside or the clinic. The scientific method and rules of evidence are as integral a part of clinical practice as the "art of medicine."

Let us consider the role of the academic pediatric scientist. Aside from personal endeavors in research, the pediatric scientist can contribute to the research environment of the department, introduce the excitement of the new frontier of the biologic sciences, act as bridge to basic science groups, develop a network or consortium of biomedical scientists who are addressing common problems, and function as role models and mentors. To be successful as a researcher, the academic pediatric scientist needs solid blocks of uncommitted time for research. Now more than ever before, professionalism is required for a successful career as an academic pediatric scientist. Time and scholarship lead to productivity; stimulating colleagues serve as catalysts. Lack of time for research and scholarship coupled with financial distress is the path to failure and frustration. With this freedom comes responsibility and expectation of creative scholarship and research. Mutual support, respect, understanding, and collegiality are essential among our diverse pediatric faculty to pursue our common goals. "Let the Walls Come Tumbling Down."

In this era of fiscal restraint, departments of pediatrics do not have the resources to develop more than a few "steeples of excellence"; that is, units that have earned national if not international renown for their contributions to clinical pediatrics and biomedical science. As a number of recent surveys of departments of the natural and behavioral sciences in research universities have demonstrated, the quality of the faculty is clearly more important than quantity. Nonetheless, a critical mass of talented faculty and resources is essential for the creation of a steeple of excellence. Moreover, steeples beget steeples. I would urge every department to foster the development of at least one such center of excellence in the biomedical, behavioral, or biosocial sciences.

Some of what I have discussed may seem a radical departure from the present role and practices of departments of pediatrics. I am reminded of a comment by Abraham Flexner: "We must not overlook the important role that extremists play. They are the gadflies that keep society from being too complacent, or selfsatisfied; they are if sound, the spearhead of progress." If I have stimulated you to confront the need for redirection and realignment in academic pediatrics, I will have fulfilled my role.

Finally, let us consider the importance of political and social activism by our Society and the Society for Pediatric Research. Mildred Stahlman's call for action, in her impassioned Presidential Address to this Society, ended for the foreseeable future any question about the responsibility of the American Pediatric Society in public affairs. Galvanized by the Baby Doe issue, the two Societies along with the AMSPDC formed the Public Policy Council in 1984, headed by Myron Genel. Under his able and dedicated leadership, the Council was charged with working in concert with the American Academy of Pediatrics on social and political issues concerned with child health, the access to health care, and research and education.

Although a host of examples could be discussed, let me mention one of special concern to academic pediatrics-the development of the NICHD initiative for Child Health Research Centers with focus on basic science, which arose, in part, out of the early success of the PSTP. Congress responded quickly to the NICHD request, no doubt encouraged by the lobbying efforts of the American Academy of Pediatrics and its over $40000 \mathrm{mem}$ bers. Less than 1 year after Congress received the request, $\$ 2$ million of NICHD 1990 funds were earmarked to establish Child Health Research Centers in academic pediatric departments. The remarkable collegiality between the academic and practicing community, bound together in a common cause, made it happen. On behalf of the American Pediatric Society, I applaud the American Academy of Pediatrics on its actions, foresight, and commitment. "Let the Walls Come Tumbling Down."

We are joined in a common enterprise to protect children and to improve their health and well being. However, despite the expenditure of more than $11 \%$ of the gross national product last year (about $\$ 600$ billion) on health care, our nation's health care system is in crisis. It is estimated that 50 million Americans have inadequate health insurance and as many as 35 million have none at all. We rank 20th among industrialized nations in the infant mortality rate. Recently, the National Commission on Children, chaired by Senator Jay Rockefeller of West Virginia, issued an interim report stating that America is "failing its children." One child in five lives below the poverty level, an increase of $5 \%$ since 1970, and is at risk for a litany of long-term medical and social problems. All this during a period of economic growth in the most well-to-do nation in the world. What a shameful indictment of our national priorities! If we are going to make the health care of children a priority, we have our work cut out for us! The demilitarization of the American economy during this decade affords a window of opportunity to redirect the national agenda.

When the next generation of pediatricians looks back on this era, let them say we laid the groundwork for a new Golden Age of Child Health and Well Being. We marshalled resources and exploited new opportunities for an unprecedented assault on the health problems of the world's children.

Finally, there are may good things about being a pediatrician in academic medicine; one of the best is the company you keep.

Thank you. 